\title{
The sol-gel entrapment of noble metals in hybrid silicas: a molecular insight
}

\author{
Alexandra Fidalgo ${ }^{1}$, Rosaria Ciriminna ${ }^{2}$, Luís Lopes ${ }^{1}$, Valerica Pandarus ${ }^{3}$, François Béland ${ }^{3}$, Laura M Ilharco ${ }^{\text {** }}$ \\ and Mario Pagliaro ${ }^{2 *}$
}

\begin{abstract}
Background: Why are metal nanoparticles sol-gel entrapped in ORMOSIL so active and stable? In other words, why ORMOSIL-entrapped metal nanoparticles are more active and selective than many heterogenized counterparts, including silica-entrapped noble metals?

Results: Unveiling specific interactions between MNPs and the molecular structure of ORMOSIL, this work investigates subtle structural aspects through DRIFT spectroscopy.

Conclusions: The results point to interactions between entrapped Pd and Pt nanocrystallites with the organosilica sol-gel cages similar to those taking place in enzymes.
\end{abstract}

Keywords: Sol-gel, Encapsulation, Heterogeneous catalysis, Metal nanoparticle, ORMOSIL

\section{Introduction}

Supported metal nanoparticles (MNPs) catalyze a number of reactions of enormous relevance in the petrochemical industry such as hydrogenation, epoxidation and monomer synthesis [1]. In the last two decades, the use of supported metal nanoparticles in synthetic organic chemistry has been extensively investigated in light of their ability to catalyze a range of chemical reactions [2], including asymmetric syntheses [3]. The aim was, and is, to apply heterogeneous catalysis to the synthesis of pharmaceutical and fine chemical products, for which the amount of effluent per tonne of product is orders of magnitude higher than that for a commodity chemical [4]. As a results of these efforts a number of new solid catalysts and green chemical processes are slowly being adopted by industry [5]; despite many remarkable research achievements like, as representative example, $\mathrm{Cu}$ ions immobilized on functionalized silica as recyclable and truly heterogeneous catalyst for the homocoupling of terminal alkynes in the presence of oxygen only [6].

\footnotetext{
* Correspondence: lilharco@ist.utl.pt; mario.pagliaro@cnr.it

${ }^{1}$ Centro de Química-Física Molecular and IN - Institute of Nanoscience and Nanotechnology, Instituto Superior Técnico, Complexo I, Av. Rovisco Pais 1, Lisboa 1049-001, Portugal

${ }^{2}$ Istituto per lo Studio dei Materiali Nanostrutturati, CNR, via U. La Malfa 153, Palermo 90146, Italy

Full list of author information is available at the end of the article
}

In general, the atomic structure of the exposed surfaces of the active "naked" nanoparticles is made of plentiful unsaturated sites capable to adsorb and catalyze conversion of the reactants [7]. For example, Pd nanoparticles, which are well known for their catalytic activities, can easily aggregate to form Pd-black because of the very high surface energy of palladium [8]. Many efforts have been devoted to develop sinter-proof catalysts using, for example, pre-prepared colloidal metal nanoparticles with tuned size, shape and composition that are then "embedded" by porous support shells [9].

In principle, the heterogenization of MNPs should prevent the tendency of atoms of "naked" MNPs to aggregate into a bulk material due to their high surface energies, which results in rapid decrease in their intrinsic catalytic activity and selectivity over time [10]. Unfortunately, however, most heterogeneous catalysts reported in the literature, and especially palladium-based catalysts [11], act as reservoir for MNPs that are leached in solution where they catalyze reaction, but also rapidly aggregate resulting in spent catalyst of poor residual activity.

Sintering is caused by mobility of the metal particles on the support surfaces. Hence, to solve the sintering problem, the encapsulation of the metal nanoparticles within oxide architectures would minimise agglomeration and ensure catalyst recyclability. The validity of this approach was shown, for example, by McFarland 
and co-workers, comparing the catalytic performance of $\mathrm{Pd}$ particles deposited on the outer surface silica $(\mathrm{Pd} /$ $\mathrm{SiO}_{2}$ ), or encapsulated within the silica inner porosity $\left(\mathrm{Pd} @ \mathrm{SiO}_{2}\right)$ [12].

In this context, we have recently introduced a new catalyst series made of Pd and Pt nanocrystals encapsulated in one-step within the sol-gel cages of mesoporous organosilica xerogels. These materials are highly selective mediators in a number of important reactions including carbon-carbon coupling [13], debenzylation [14], highly selective hydrogenation of functionalized nitroarenes [15] and vegetable oils [16], and hydrosilylation of olefins [17]. Applications are not limited to this broad class of reactions and we are continuing to investigate new reactions and synthetic applications.

Work reported in this account investigates the structural origins of the enhanced performance of these new entrapped metal catalysts by Diffuse Reflectance Infrared Fourier Transform (DRIFT) spectroscopy, which is a powerful spectroscopic technique to investigate the molecular structure of these materials, revealing the subtle structural factors affecting their performance. Surface methods, indeed, are not suitable to investigate these materials due to the sol-gel encapsulation of the active species within the pores of the matrix.

\section{Results and discussion}

These novel catalytic materials typically contain $\operatorname{Pd}(0)$ or $\mathrm{Pt}(0)$ as the nanophase in hybrid alkyl-modified silica materials. For example, two catalysts made from methyl-triethoxysilane (MTEOS, Figure 1) doped with

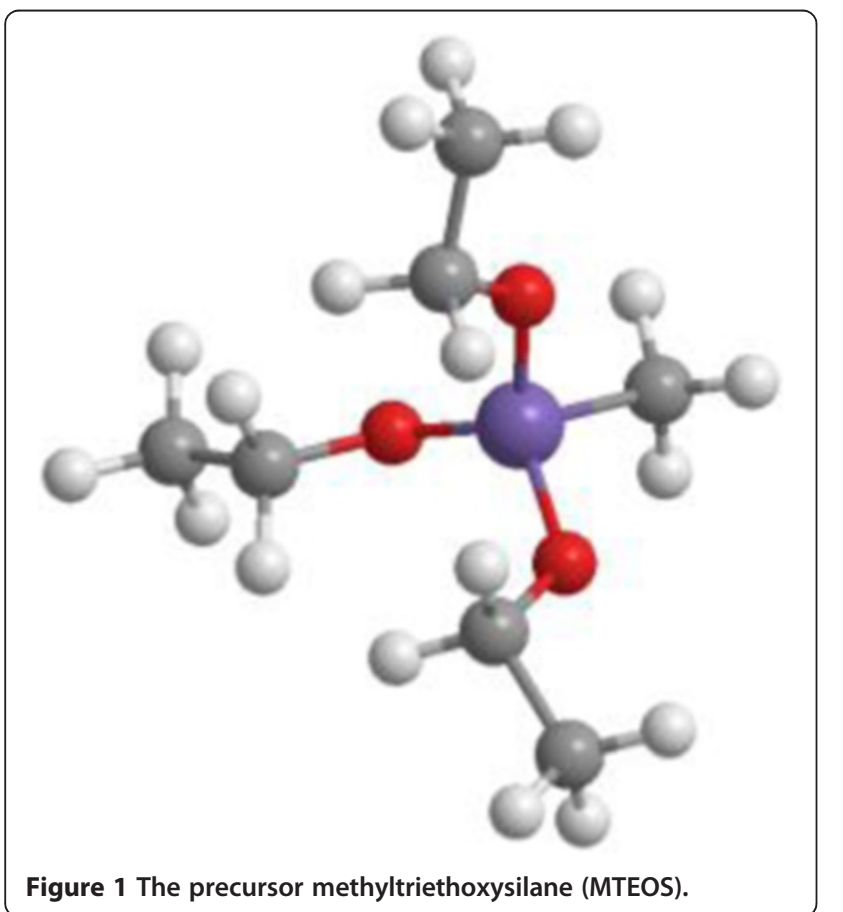

$\operatorname{Pd}(0)$ and $\operatorname{Pt}(0)$ were prepared according to the hydrolytic polycondensation process for the precursor MTEOS:

$$
\begin{aligned}
& -\mathrm{EtOH} \\
& \mathrm{MeSi}(\mathrm{OEt})_{3}+\text { catayst }+\mathrm{H}_{2} \mathrm{O} \\
& \rightarrow \text { catayst@ }\left[\mathrm{Me}-\mathrm{SiO}_{\mathrm{n}} \mathrm{H}_{\mathrm{m}}(\mathrm{OEt})_{\mathrm{q}}\right]_{\mathrm{p}}(1) \text {, unbalanced }
\end{aligned}
$$

Efficient entrapment of Pd or Pt nanoparticles is achieved by removing the released alcohol, using rotavapor distillation. Classical sol-gel encapsulation based on hydrolytic polycondensation of Si alkoxides releases large amounts of alcohol that rapidly reduce the $\mathrm{Pd}^{2+} / \mathrm{Pt}^{2+}$ ions to bulk $\mathrm{Pd}(0) / \mathrm{Pt}(0)$. The latter metal species are catalytically inactive, as only nanostructured MNPs are able to catalyze reactions, such as Pd nanoparticles mediating C-C coupling reactions [8].

Here instead, the resulting alcohol-free sol is doped with a $\mathrm{Pd}(\mathrm{II})$ or $\mathrm{Pt}(\mathrm{II})$ species, and undergoes further basic or acid catalyzed polycondensation to yield a mesoporous hydrogel that is dried under mild conditions to afford a xerogel doped with $\mathrm{Pd}^{2+} / \mathrm{Pt}^{2+}$. The latter material is chemically reduced under mild conditions to yield a mesostructured encapsulated catalyst in which the MNPs are physically and chemically stabilized, affording materials that can safely be used, without the need to exclude air or moisture. The TEM images clearly show the amorphous structure of the ORMOSIL embedding matrix structure in either catalyst. For SiliaCat $\mathrm{Pt}^{0}$ (Figures 2A and Figure 2B), there is a considerable density of metallic $\mathrm{Pt}^{0}$ nanocrystallites with average diameter of $\sim 16 \mathrm{~nm}$, whereas for SiliaCat $\mathrm{Pd}^{0}$ both the density and dimensions of the $\mathrm{Pd}^{0}$ crystallites are smaller (Figure $2 \mathrm{C}$ ), pointing to a size of $\sim 8 \mathrm{~nm}$.

The $\mathrm{N}_{2}$ adsorption-desorption isotherms at $77 \mathrm{~K}$ of the two catalysts are shown and compared in Figure 3. For pore size evaluation we used the equation of Harkins and Jura [18]. Hence, the graphs next to the BET reports are the desorption $d V / d D$ pore volume: Harkins and Jura plot with FAAS correction.

According to the IUPAC classification, the isotherms are type IV with hysteresis loops close to type H1, characteristic of capillary condensation in open cylindrical mesopores between spheroidal particles of fairly uniform array [19]. The mesopore size distribution using the $\mathrm{BJH}$ algorithm (that assumes a cylindrical pore shape) has a maximum population at $\sim 9 \mathrm{~nm}$ for SiliaCat $\mathrm{Pt}^{0}$ and $6 \mathrm{~nm}$ for SiliaCat $\operatorname{Pd}^{0}$. The values of parameter $c$ in the BET equation (99 for SiliaCat $\mathrm{Pd}^{0}$ and 79.3 for SiliaCat $\mathrm{Pt}^{0}$ ) and the $t$-plot analysis (Harkins and Jura) both indicate that there is no contribution from micropores in either sample. The textural parameters are summarized in Table 1.

Both structures have a very large surface area, exceeding $700 \mathrm{~m}^{2} / \mathrm{g}$. SiliaCat $\mathrm{Pd}^{0}$, however, has significantly 


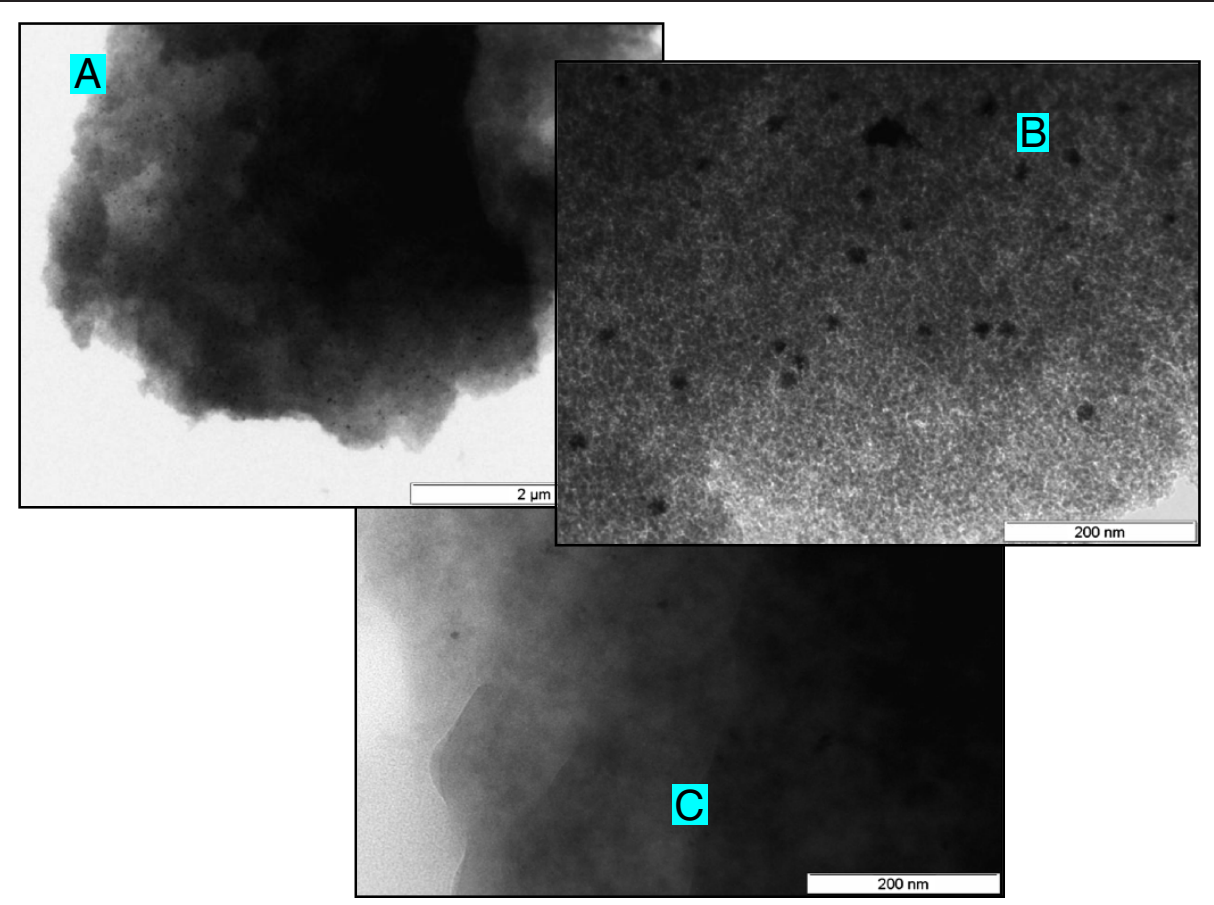

Figure 2 TEM images of the microstructure of: $\mathrm{A}$ and $\mathrm{B}-$ SiliaCat $\mathrm{Pt}^{0} ; \mathrm{C}-\mathrm{SiliaCat} \mathrm{Pd}^{0}$.

lower total pore volume. Accordingly, the average mesopore size is smaller for SiliaCat $\mathrm{Pd}^{0}$, but the size distribution is in either case peaked, pointing to negligible populations of smaller and larger pores.

The (DRIFT) spectra for both catalysts are shown in Figure 4.

The spectra of the two catalysts are very similar, with only slight changes in the relative intensities of some bands. The proposed band assignments are summarized in Table 2.

Given the high level of methylation of these matrices, it does not come as a surprise that both catalysts are hydrophobic. This is shown by the very weak $v(\mathrm{O}-\mathrm{H})$ band and absence of the $\delta(\mathrm{HOH})$ mode, expected at $\sim 1640 \mathrm{~cm}^{-1}$ if any water molecules were adsorbed. The $v(\mathrm{O}-\mathrm{H})$ band is therefore assigned to residual silanol ( $\mathrm{Si}-\mathrm{OH})$ groups. The very low intensities of this band and of the $\mathrm{vSi}-\mathrm{O}(\mathrm{H})$ or $\mathrm{Si}-\mathrm{O}^{-}$(at $\sim 924 \mathrm{~cm}^{-1}$ ) bands show that the condensation reactions were extremely efficient. In addition, the high wavenumber of the $v(\mathrm{O}-\mathrm{H})$ band maximum $\left(\sim 3500 \mathrm{~cm}^{-1}\right)$ indicates that the very few silanol groups are not strongly interacting by hydrogen bonds [22].

The two bands at 2974 and $2914 \mathrm{~cm}^{-1}$ are assigned to the stretching modes (antisymmetric and symmetric, respectively) of the methyl groups bonded to a silicon atom. The corresponding deformation modes appear at 1410 and $1273 \mathrm{~cm}^{-1}$, respectively. The absence of $\mathrm{CH}_{2}$ related bands certifies that hydrolysis of methyltriethoxysilane was complete.
The two catalysts are thus hydrophobic and lipophilic. The visible bands in the spectra are assigned in Table 2, but the detailed assignment may only be confidently proposed after band deconvolution in two regions: i) $950-1250 \mathrm{~cm}^{-1}$, which corresponds to the silica structural fingerprint, the $v_{\mathrm{as}} \mathrm{Si}$-O-Si mode, split in two observable components, with maxima at $\sim 1130$ and $\sim 1036 \mathrm{~cm}^{-1}$, $\mathrm{cm}^{-1}$; ii) $700-900 \mathrm{~cm}^{-1}$, which apparently corresponds to two bands with maxima at 781 and $852 \mathrm{~cm}^{-1}$, but in fact contains a number of overlapping components. The deconvolution of these spectral regions in a sum of Gaussian components was made by a non-linear least squares fitting method, previously described [23]. The deconvolution profiles are shown in Figure 5.

The results concerning the $950-1250 \mathrm{~cm}^{-1}$ region are summarized in Table 3, while those regarding the 700 and $900 \mathrm{~cm}^{-1}$ region are given in Table 4 .

The $v_{\text {as }} \mathrm{Si}$-O-Si mode was decomposed in longitudinal and transverse optical components (LO and TO, respectively) of different siloxane rings: six-member $\left[(\mathrm{SiO})_{6}\right]$ and four-member $\left[(\mathrm{SiO})_{4}\right]$. The relative intensities of the components related to the four-member rings are much smaller indicating that the primary structure of the catalysts is predominantly formed by six-member siloxane rings: both ORMOSIL structures contain $\sim 80 \%$ of six-member siloxane rings (Figure $6 \mathrm{~A}$ ) and $\sim 20 \%$ of four-member siloxane rings (Figure $6 \mathrm{~B}$ ). These rings indeed are less tensioned, and more suitable to accommodate the extremely high content in 


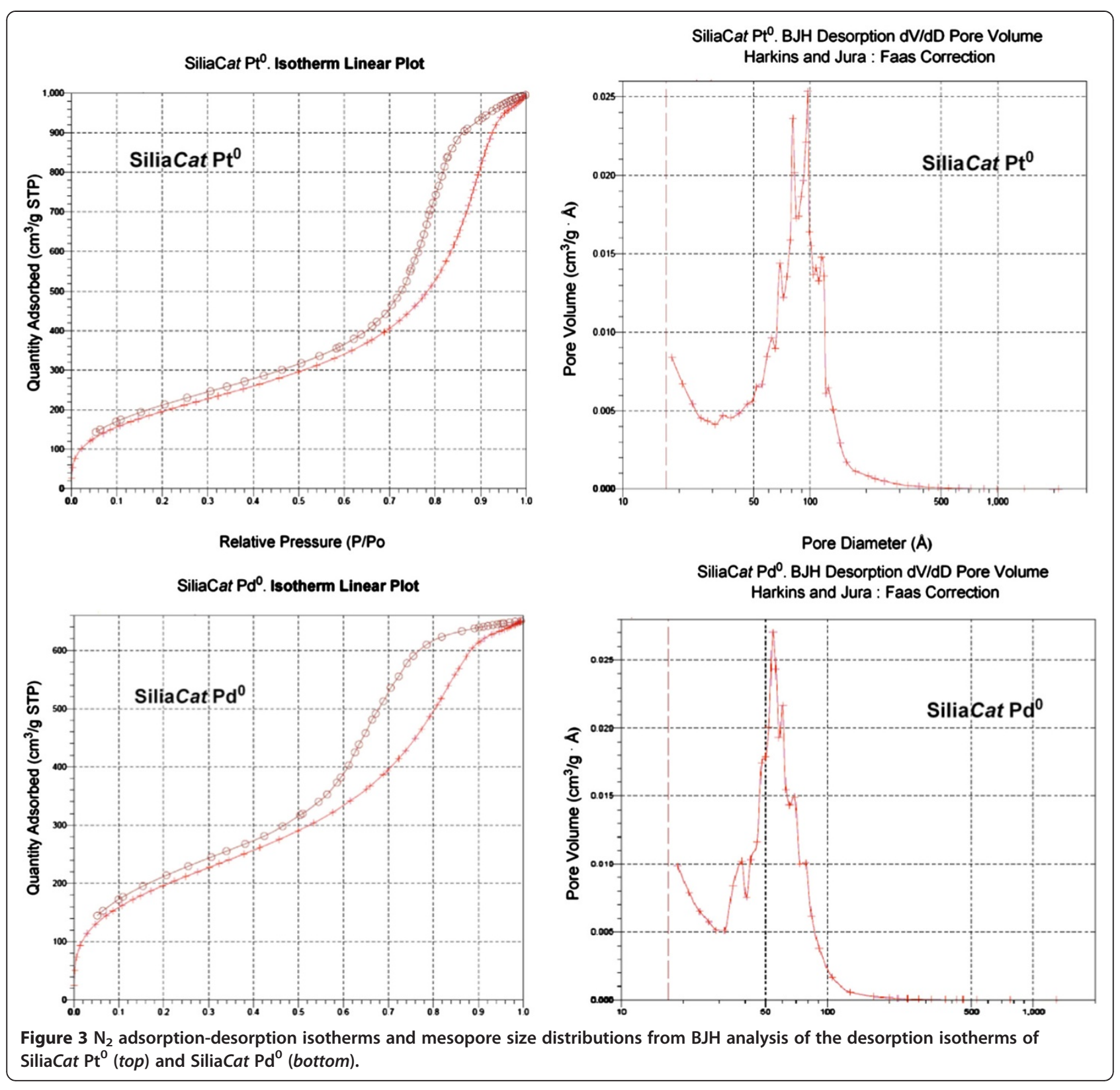

methyl groups bonded to the $\mathrm{Si}$ atoms. An arrangement of four-member units would yield a much less three dimensional network, as only the terminal $\mathrm{Si}$ atoms are able to continue condensation. For undoped ORMOSILs produced from a mixture of trimethoxysilane (TMOS) and methyl-trimethoxysilane (MeTMOS), a similar result was obtained when the methylation degree was higher than $75 \%$ [24].

Accordingly, previous preliminary investigation of the SiliaCat $\mathrm{Pd}^{0}$ structure by solid state NMR [25] has shown that the degree of cross-linking does not correlate with the catalytic activity.

Table 1 Textural parameters of SiliaCat $\mathrm{Pd}^{0}$ and SiliaCat $\mathrm{Pt}^{0}$ from the $\mathrm{N}_{2}$ adsorption-desorption isotherms

\begin{tabular}{lllll}
\hline Sample & $\begin{array}{l}\text { BET specific surface } \\
\text { area }\left(\mathbf{m}^{2} / \mathbf{g}\right)\end{array}$ & $\begin{array}{l}\text { Total pore } \\
\text { volume }\left(\mathbf{c m}^{\mathbf{3}} / \mathbf{g}\right)^{a}\end{array}$ & $\begin{array}{l}\text { BJH desorption average } \\
\text { mesopore diameter }(\mathbf{n m})^{b}\end{array}$ & Metal loading (mmol/g) \\
\hline SiliaCat $\mathrm{Pd}^{0}$ & $706 \pm 4.1$ & 1.01 & 5.7 & 0.05 \\
SiliaCat $\mathrm{Pt}^{0}$ & $712 \pm 2.9$ & 1.54 & 8.7 & 0.1 \\
\hline
\end{tabular}

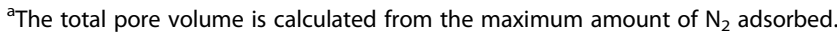

${ }^{b}$ The average mesopore diameter is calculated from $d=4$ V/S (BET surface area). 


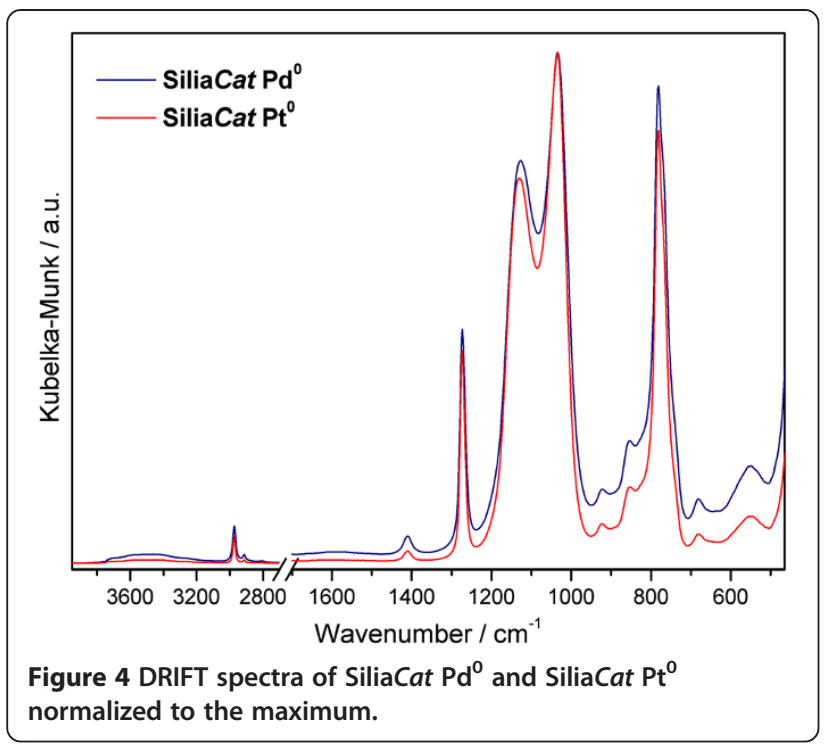

Therefore, a predominantly six-member network is perfectly compatible with the porous structure found. Given the low content in four-member siloxane rings, the band at $\sim 550 \mathrm{~cm}^{-1}$, which is usually assigned to a coupled mode in these units, must have some contribution from defective structures [26], possibly associated with $\mathrm{Pd}(\mathrm{II})$ and $\mathrm{Pt}(\mathrm{II})$ species that were not reduced.

Elimination of ethanol from the alcogel mixture contributes to the very large porosity observed in these hydrogel-derived catalysts. Indeed, the capillary tension at the solid-water cage interface is greatly reduced

Table 2 Assignments of the visible bands in the DRIFT spectra of SiliaCat $\mathbf{P d}^{0}$ and SiliaCat $\mathrm{Pt}^{0}$

\begin{tabular}{|c|c|c|}
\hline \multicolumn{2}{|c|}{ Wavenumber $/ \mathrm{cm}^{-1}$} & \multirow{2}{*}{$\begin{array}{l}\text { Assignments } \\
{[20,21]}\end{array}$} \\
\hline SiliaCat $\mathrm{Pt}^{\mathrm{O}}$ & SiliaCat $\mathbf{P d}^{0}$ & \\
\hline 3500 (broad) & $\sim 3500$ (broad) & $\mathrm{VO}-\mathrm{H}$ \\
\hline $2974_{w}$ & $2972_{w}$ & $\mathrm{~V}_{\mathrm{as}}(\mathrm{Si}) \mathrm{CH}_{3}$ \\
\hline $2914_{v w}$ & $2914_{v w}$ & $\mathrm{~V}_{5}\left(\mathrm{Si}_{\mathrm{i}}\right) \mathrm{CH}_{3}$ \\
\hline $1410_{w}$ & $1410_{w}$ & $\delta_{\mathrm{as}}(\mathrm{Si}) \mathrm{CH}_{3}$ \\
\hline $1273_{s}$ & $1273_{m}$ & $\delta_{5}\left(\mathrm{Si}_{i}\right) \mathrm{CH}_{3}$ \\
\hline 1130 vs & $1126 \mathrm{vs}$ & $\mathrm{V}_{\mathrm{as}} \mathrm{Si}-\mathrm{O}-\mathrm{Si}$ \\
\hline $1036 v s$ & 1034 vs & $\mathrm{v}_{\mathrm{as}} \mathrm{Si}-\mathrm{O}-\mathrm{Si}$ \\
\hline $924_{v w}$ & $922_{\mathrm{vw}}$ & $v S i-O_{d}$ \\
\hline $852_{w}$ & $854_{w}$ & $\omega(\mathrm{Si}) \mathrm{CH}_{3}$ \\
\hline 781vs & $781_{\text {vs }}$ & $\rho(\mathrm{Si}) \mathrm{CH}_{3}$ \\
\hline $681_{w}$ & $681_{w}$ & vSi-C \\
\hline $546_{w}$ & $550_{w}$ & $(\mathrm{SiO})_{4}$ rings \\
\hline
\end{tabular}

preventing collapse of the gel during drying [27]. Also, elimination of $\mathrm{EtOH}$ favours the $\mathrm{Si}$ alkoxide monomers hydrolysis and slows down condensation, so that rapid aggregation of the early sol particles is prevented and MTEOS can fully hydrolyse to $\mathrm{CH}_{3}-\mathrm{Si}(\mathrm{OH})_{3}$, which undergoes polycondensation in an open, amorphous structure made predominantly of 6-membered siloxane rings, entrapping Pd or Pt metallic nanophases with the well-known sol-gel stabilization of the nanoparticles.

The spectral region between 700 and $900 \mathrm{~cm}^{-1}$ is more difficult to decompose, given the number of overlapping components with close frequencies. The assignment in this region is not straightforward, because $\mathrm{Si}-\mathrm{C}$ stretching modes are expected, with different frequencies depending on the local structure [28].

An interesting feature of these decompositions is that the $v_{s} \mathrm{Si}-\mathrm{O}-\mathrm{Si}$ band is in fact present, although not resolved. The similarity between the two decompositions confirms the resemblance between the molecular structure of the two catalysts.

The atomic dimension and electronegativity of the metal do not influence the main characteristics of the matrix structure: Pt belongs to the same group and to the following period as Pd (it is much larger and with higher electronegativity). Nevertheless, the ORMOSIL morphology and the dispersion of the metal nanophase are quite different. We emphasize herein the relevance of the support embedding structure in guiding and dictating the access of the reactants to the entrapped nanophase. In other words, encapsulation of the metal nanoparticles within the ORMOSIL structures results in materials that are remarkably more active than traditional catalysts; and this generally allows use of an ultralow amount of valued catalyst under conditions that are milder than those of state-of-the-art processes.

For instance, a $0.05 \mathrm{~mol} \%$ amount of SiliaCat $\operatorname{Pd}(0)$ entrapped catalyst can be used to mediate the complete hydrogenation of a wide variety of vegetable oils under hydrogen balloon conditions without cis/ trans isomerisation; ${ }^{16}$ whereas the best Pd catalyst previously known, made of Pd nanoparticles entrapped in the hexagonal porosity of SBA-15 mesoporous silica, mediates less selectively the same conversion at $100^{\circ} \mathrm{C}$ under 5 atm $\mathrm{H}_{2}$ [29]. Similar findings have been reported for most of the catalytic processes catalyzed by the SiliaCat $\mathrm{Pd}^{0}$ and SiliaCat $\mathrm{Pt}^{0}$ mentioned above.

\section{Conclusions}

The DRIFT investigation of the molecular structure of ORMOSIL-entrapped metal nanoparticles suggests that the mechanism of action of nanoparticles encapsulated in organosilica is similar to that of enzymes. Once the metal nanoparticles are encapsulated and stabilized 

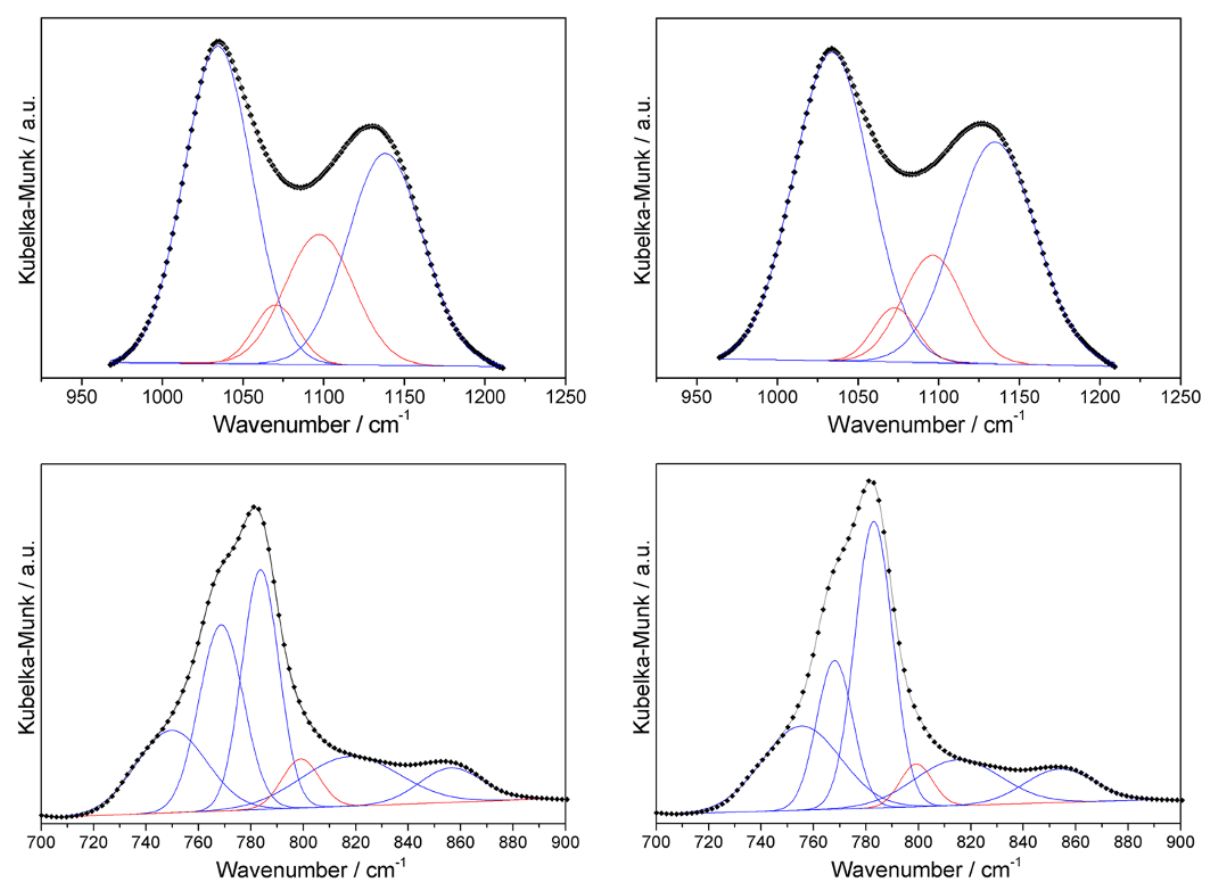

A

B

Figure 5 Deconvolution of the DRIFT spectra in the $950-1250 \mathrm{~cm}^{-1}$ and $700-900 \mathrm{~cm}^{-1}$ regions: A: SiliaCat $\mathrm{Pd}^{0}$; $\mathrm{B}-\mathrm{SiliaCat}^{\mathrm{Pt}}{ }^{0}$.

within the sol-gel cages, it is the hydrophilic-lipophilic balance (HLB) of the matrix that dictates access and optimal catalysis with unprecedented performance, by promoting preferential adsorption of the lipohilic functional group moieties in reacting substrates adsorbed at the surface of the Pd and Pt nanoparticles in reactions as different as hydrogenation of fats, hydrogenation alkenes and nitroarenes, hydrosilylation of olefins and C-C coupling.

The above mentioned reactions concern very large sectors of the chemical industry, many of which continue to use obsolete catalysts such as $\mathrm{Ni}$ Raney

Table 3 Results of the deconvolution of the $950-1250 \mathrm{~cm}^{-1}$ spectral region of the DRIFT spectra: components' center in $\mathrm{cm}^{-1}$ and relative areas (in\%)

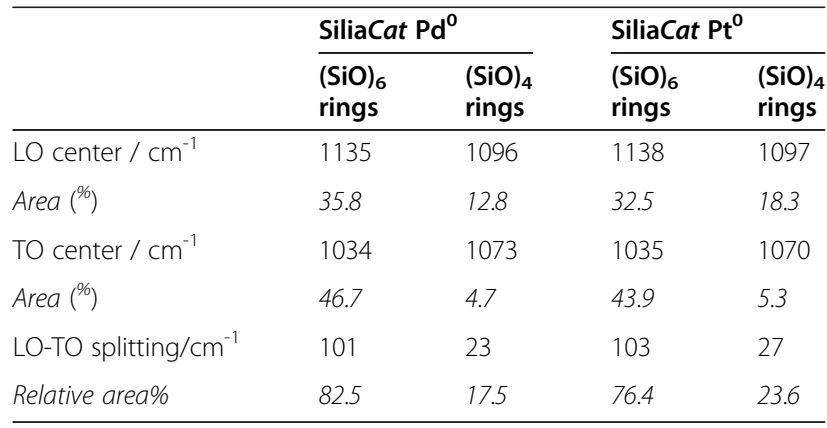

(hydrogenation of fats), or $\mathrm{Pt} / \mathrm{C}$ (hydrogenation of olefins). Sol-gel entrapped metal nanophases will give an immense contribute to simplify those processes, whereas new catalysts are being developed capable to target other relevant reactions.

\section{Experimental section}

\section{Materials synthesis}

In a typical preparation, a mixture of methyltriethoxysilane (27 g, $30 \mathrm{~mL}, 151.4 \mathrm{mmol}$ ) and $10 \mathrm{~mL}$ of $0.042 \mathrm{M} \mathrm{HCl}$ was stirred for 15 minutes. The resulting solution was concentrated with a rotavapor under reduced pressure at $30^{\circ} \mathrm{C}$

Table 4 Results of the deconvolution of the $700-900 \mathrm{~cm}^{-1}$ spectral region of the DRIFT spectra: components' center in $\mathrm{cm}^{-1}$ and relative areas (in\%)

\begin{tabular}{|c|c|c|c|c|}
\hline \multirow[t]{2}{*}{ Assignments } & \multicolumn{2}{|l|}{ SiliaCat $\mathrm{Pd}^{0}$} & \multicolumn{2}{|l|}{ SiliaCat $\mathrm{Pt}^{0}$} \\
\hline & $\begin{array}{l}\text { Band } \\
\text { center } / \mathrm{cm}^{-1}\end{array}$ & Area (\%) & $\begin{array}{l}\text { Band } \\
\text { center } / \mathrm{cm}^{-1}\end{array}$ & Area (\%) \\
\hline$\omega(\mathrm{Si}) \mathrm{CH}_{3}$ & 856 & 6.8 & 854 & 7.9 \\
\hline vSi-C & 818 & 15.3 & 815 & 12.8 \\
\hline$v_{s} \mathrm{Si}-\mathrm{O}-\mathrm{Si}$ & 799 & 5.8 & 799 & 4.7 \\
\hline$\rho(\mathrm{Si}) \mathrm{CH}_{3}$ & 784 & 27.7 & 783 & 35.9 \\
\hline$\rho(\mathrm{Si}) \mathrm{CH}_{3}$ & 769 & 26.2 & 768 & 17.3 \\
\hline vSi-C & 749 & 18.2 & 755 & 21.4 \\
\hline
\end{tabular}




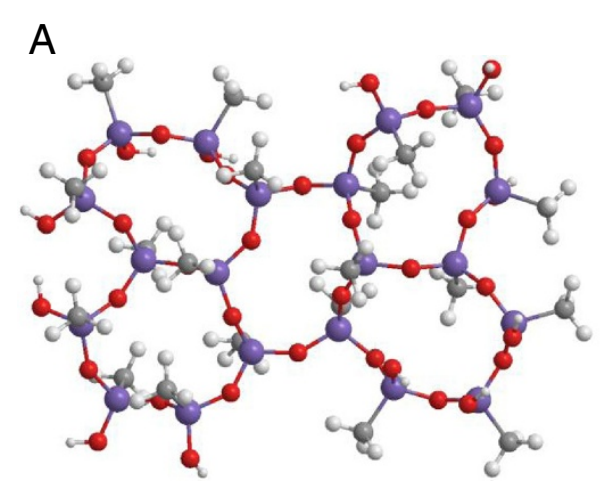

B

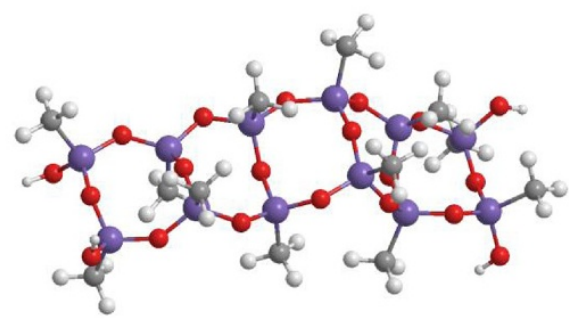

Figure 6 Schematic representation of a silica cluster containing five cyclic siloxane units: A-six-member [(SiO) 6 ; B - four member $\left[(\mathrm{SiO})_{4}\right]$.

until complete ethanol removal (about 15 minutes). The alcohol-free sol thereby obtained was added with $\mathrm{K}_{2} \mathrm{PdCl}_{4}$ (from 0.004 to 0.02 equivalent) dissolved in $\mathrm{H}_{2} \mathrm{O}$ (from 5 to $10 \mathrm{~mL}$ ) and $60 \mathrm{~mL}$ acetonitrile. This mixture was added with $1 \mathrm{M} \mathrm{NaOH}$ (from 0.023 to 0.053 equivalent) to favour gelation that indeed rapidly occurred. The resulting transparent gel was left to dry in air for 4 days after which the xerogel was reduced at room temperature under inert conditions with a solution of sodium triacetoxyborohydride (Pd: $\mathrm{Na}(\mathrm{AcO})_{3} \mathrm{BH}=1: 6$ molar ratio) in $80 \mathrm{~mL}$ THF, washed with THF and $\mathrm{H}_{2} \mathrm{O}$ and dried in air to afford a SiliaCat $\mathrm{Pd}^{0}$ catalyst. The metal load in each catalyst was measured using the CAMECA SX100 instrument equipped with EPMA analyzer, a fully qualitative and quantitative method of non-destructive elemental analysis of micron-sized volumes at the surface of materials, with sensitivity at ppm level.

\section{DRIFT analysis}

Fourier transform spectroscopy in diffuse reflectance mode was performed in a Mattson RS1 FTIR spectrometer with a Graseby Specac Selector, in the range 400-4000 $\mathrm{cm}^{-1}$, at $4 \mathrm{~cm}^{-1}$ resolution. The analyses were carried out at ambient temperature and pressure, using a powder catalyst sample as received by the catalysts manufacturer (SiliCycle, Inc.). No further treatment of the catalyst was undertaken prior to measurement.

\section{TEM analysis}

The TEM pictures were obtained in an electron microscope Hitachi H-8100, operated at $200 \mathrm{kV}$, with a LaB6 filament. The samples were dispersed in ethanol and then dropped onto a Formvar ${ }^{\bullet}$-coated $\mathrm{Cu}$ grid and left to evaporate.

\section{BET analysis}

Nitrogen adsorption and desorption isotherms at $77 \mathrm{~K}$ were measured using a an ASAP 2020 system from Micromeritics, analyzing the resulting data with the Tristar 3000 software (version 4,01). The desorption branch was used to calculate the pore size distribution.

\section{Competing interests}

The authors declare that they have no competing interests.

\section{Authors' contributions}

All authors contributed equally to this work. All authors read and approved the final manuscript.

\section{Acknowledgements}

This paper is dedicated to University of Palermo's Professors Ines Donato and Pasquale Agozzino In memory of a wonderful student trip in 1992, just one gift out of many to their students. Thanks to Mr Simon Bédard from the Quality Control Department of SiliCycle Inc. for his valuable contribution to the adsorption measurements.

\section{Author details}

${ }^{1}$ Centro de Química-Física Molecular and IN - Institute of Nanoscience and Nanotechnology, Instituto Superior Técnico, Complexo I, Av. Rovisco Pais 1, Lisboa 1049-001, Portugal. ${ }^{2}$ Istituto per lo Studio dei Materiali Nanostrutturati, CNR, via U. La Malfa 153, Palermo 90146, Italy. ${ }^{3}$ SiliCycle Inc., 2500,

Parc-Technologique Blvd, Quebec City, Quebec G1P 4S6, Canada.

Received: 4 June 2013 Accepted: 16 September 2013

Published: 30 September 2013

\section{References}

1. Anderson JA, Garcia MF: Supported Metals in Catalysis. London (UK): Imperial College Press; 2005.

2. Astruc D, Lu F, Ruiz Aranzaes J: Nanoparticles as recyclable catalysts: the frontier between homogeneous and heterogeneous catalysis. Angew Chem Int Ed 2005, 44:7852-7872.

3. Barbaro P, Dal Santo V, Liguori F: Emerging strategies in sustainable finechemical synthesis: asymmetric catalysis by metal nanoparticles. Dalton Trans 2010, 39:8391-8402.

4. Busacca CA, Fandrick DR, Song JJ, Senanayake CH: The growing impact of catalysis in the pharmaceutical industry. Adv Synth Catal 2011, 353:1825-1864.

5. Lucarelli C, Vaccari A: Examples of heterogeneous catalytic processes for fine chemistry. Green Chem 2011, 13:1941-1949.

6. van Gelderen L, Rothenberg G, Calderone VR, Wilson K, Shiju NR: Efficient alkyne homocoupling catalysed by copper immobilized on functionalized silica. Appl Organomet Chem 2013, 27:23-27. 
7. Lee I, Morales R, Albiter MA, Zaera F: Synthesis of heterogeneous catalysts with well shaped platinum particles to control reaction selectivity. Proc Natl Acad Sci U S A 2008, 105:15241-15246.

8. Reetz MT, De Vries JG: Ligand-free Heck reactions using low Pd-loading. Chem Commun 2004:1559-1563.

9. Jia CJ, Schüth F: Colloidal metal nanoparticles as a component of designed catalyst. Phys Chem Chem Phys 2011, 13:2457-2487.

10. Moulijn JA, van Diepen AE, Kapteijn F: Catalyst deactivation: is it predictable? - What to do? Appl Catal A Gen 2001, 212:3-16.

11. Pagliaro M, Pandarus V, Ciriminna R, Beland F, Demma Cara P: Heterogeneous versus Homogeneous Palladium Catalysts for CrossCoupling Reactions. Chem CatChem 2012, 4:432-445.

12. Forman AJ, Park JN, Tang W, Hu YS, Stucky GD, McFarland EW: SilicaEncapsulated Pd Nanoparticles as a Regenerable and Sintering-Resistant Catalyst. ChemCatChem 2010, 2:1318-1324.

13. Pagliaro $M$, Pandarus V, Béland F, Ciriminna R, Palmisano G, Demma Carà P: A new class of heterogeneous Pd catalysts for synthetic organic chemistry. Catal Sci Technol 2011, 1:736-739.

14. Pandarus V, Béland F, Ciriminna R, Pagliaro M: Selective Debenzylation of Benzyl Protected Groups with SiliaCat $\mathrm{Pd}(0)$ under Mild Conditions. ChemCatChem 2011, 3:1146-1150.

15. Pandarus V, Ciriminna R, Beland F, Pagliaro M: A new class of heterogeneous platinum catalysts for the chemoselective hydrogenation of nitroarenes. Adv Synth Catal 2011, 353:1306-1316.

16. Pandarus V, Gingras G, Béland F, Ciriminna R, Pagliaro M: Selective hydrogenation of vegetable oils over SiliaCat $\mathrm{Pd}(0)$. Org Process Res Dev 2012, 16:1307-1311.

17. Ciriminna R, Pandarus V, Gingras G, Béland F, Pagliaro M: Closing the organosilicon synthetic cycle: efficient heterogeneous hydrosilylation of alkenes over SiliaCat Pt(0). ACS Sustainable Chem Engineer 2013, 1:249-253.

18. Halsey GD: Physical adsorption on non-uniform surfaces. J Chem Phys 1948, 16:931-937.

19. Gregg SJ, Sing KSW: Adsorption, Surface Area, and Porosity. 2nd edition. New York: Academic Press; 1982

20. Ciriminna R, Ilharco LM, Fidalgo A, Campestrini S, Pagliaro M: The structural origins of superior performance in sol-gel catalysts. Soft Matter 2005, 1:231-237.

21. Lin SY, Chang ST: Variations of vibrational local modes and electronic states of hydrogenated amorphous silicon carbide under thermal annealing. J Phys Chem Solids 1998, 59(9):1399-1405.

22. Socrates G: Infrared and Raman Characteristic Group Frequencies, Tables and Charts. 3rd edition. Chichester: John Wiley \& Sons; 2004.

23. Fidalgo A, Iharco LM: Chemical tailoring of porous Silica Xerogels: local structure by vibrational spectroscopy. Chem Eur J 2004, 10:392-398.

24. Fidalgo A, Ciriminna R, Ilharco LM, Pagliaro M: Role of the alkyl-alkoxide precursor on the structure and catalytic properties of hybrid sol-gel catalysts. Chem Mater 2005, 17:6686-6694.

25. Pandarus V, Béland $F$, Ciriminna $R$, Demma Carà $P$, Pagliaro $M$ : Characterization of Nanostructured SiliaCat Pd(0). Catal Letters 2012, 142:213-217.

26. Kamyia $\mathrm{K}$, Yoko T, Tanaka K, Takeuchi M: Thermal evolution of gels derived from $\mathrm{CH}_{3} \mathrm{Si}\left(\mathrm{OC}_{2} \mathrm{H}_{5}\right)_{3}$ by the sol-gel method. J Non-Cryst Solids 1990, 121:182-187.

27. De Witte BM, Commers D, Uytterhoeven JB: Distribution of organic groups in silica gels prepared from organo-alkoxysilanes. J Non-Cryst Solids 1996, 202:35-41.

28. King S, Bielefeld J: Rigidity percolation in plasma enhanced chemical vapor deposited a-SiC:H Thin Films. ECS Trans 2010, 3:185-194.

29. Belkacemi K, Boulmerka A, Arul J, Hamoudi S: Hydrogenation of vegetable oils with minimum trans and saturated fatty acid formation over a new generation of Pd-catalyst. Top Catal 2006, 37:113-120.

doi:10.1186/1752-153X-7-161

Cite this article as: Fidalgo et al:: The sol-gel entrapment of noble metals in hybrid silicas: a molecular insight. Chemistry Central Journal 2013 7:161

Publish with ChemistryCentral and every
scientist can read your work free of charge
"Open access provides opportunities to our
colleagues in other parts of the globe, by allowing
anyone to view the content free of charge."
W. Jeffery Hurst, The Hershey Company.
- available free of charge to the entire scientific community
- peer reviewed and published immediately upon acceptance
- cited in PubMed and archived on PubMed Central
- yours - you keep the copyright
Submit your manuscript here:
http://www.chemistrycentral.com/manuscript/

